\title{
Translated in Translation Studies
}

\author{
Alper Zafer GÜNEŞ*
}

The current article aims to test conceptual borders and explanatory potential of intralingual translation. It takes up from the findings of the author's previous research questioning differing approaches toward intralingual translation published in a single multiauthor volume showcasing Translation Studies research in Turkey. For the aims of the current research, Yasemin Alptekin's recent article in the same volume entitled "John Dewey's 1924 Report on Turkish Education: Progressive Education Translated out of Existence" has been examined as a case of intralingual translation into Translation Studies. This article is identified as a revised version of Alptekin's another article published in the field of education with the title "Can Progressive Education Be Translated into a Progressive Idea?: Dewey's Report on Turkish Education (1924)". In a target-oriented framework, transfer mechanisms between the two scientific fields have been scrutinized. The study approaches Alptekin's case as part of a translation system established within Translation Studies. By contextualizing her activity, possible patterns of strategies are explored, and it is hoped that the process of planning in which the revision was carried out can be understood. In this regard, the research hypothesizes that Translation Studies can illuminate revision as a translational activity with its own tools. It further proposes that scientific writing is not immune to manipulations of translation in the application of theories and highlights strong scientific reasoning against potential pitfalls.

Keywords: revision; intralingual translation; translated translation studies; scientific method; self-reflexivity

\section{Motivation}

A perceived disagreement between the approaches of two studies in the same volume, Tradition, Tension and Translation in Turkey, was the driving force behind this research project. On the one hand, Özlem Berk Albachten (2015) in "The Turkish Language Reform and Intralingual Translation" enlarges the concept of intralingual translation to include "oralto-oral or oral-to-written" transmission, "localization, précis-writing, expert-to-layman communication" or "adaptation of classics for children," but warns against translating "düzenlenmiş" (arranged) and "yayına hazırlanmış" (prepared for publishing) as editing, "simply because these [intralingual translations] involve additional processes to those we know today as editing a literary text, which does not involve translation" (171).

\footnotetext{
Translator at Abdullah Gül University, Kayseri; $\mathrm{PhDc}$ at Istanbul 29 Mayıs University. E-mail: azafergunes@gmail.com
} 
On the other hand, Yasemin Alptekin (2015) in “John Dewey's 1924 Report on Turkish Education: Progressive Education Translated out of Existence" makes editing the topic of her article. In editors' words, the scholar questions why "the emphasis on 'progressive' was ironically edited out and replaced by alternative phrasing or lexical terms" in "various translations" of John Dewey's English report on Turkish education (Tahir Gürçağlar, Paker, and Milton 2015a, 17; emphasis added). In the essay, this practice is classified as "a re-wording in modern Turkish" of the 1987 version of the report (Alptekin 2015, 182; emphasis added). I explored possible reasons behind this theoretical difference in a previous research presented at the BAKEA 5th International Western Cultural and Literary Studies Symposium held on 5 October, 2017 in Sivas, Turkey.

As a follow-up research, I would like to explore the limits and explanatory force of intralingual translation as a theoretical concept in this paper. In this regard, I hypothesize that revision can be analyzed as a translational activity with the tools of Translation Studies and propose that the manipulative nature of translating is also inherent in the case of scientific writings and observable in the application of theories. The unit of analysis is Yasemin Alptekin's said article. As a footnote to the title, Alptekin informs that the article in question is a "completely revised version of an earlier article that appeared in International Journal of Progressive Education 2 (2), 2006" and extends her gratitude to "William Hunter, Saliha Paker, and Şehnaz Tahir Gürçağlar for their invaluable comments on various versions" of the paper (Alptekin 2015, 181; emphasis added). As per the research proposal, Alptekin's original article "Can Progressive Education Be Translated into a Progressive Idea?: Dewey's Report on Turkish Education (1924)" is taken as the source text and the revised version "John Dewey's 1924 Report on Turkish Education: Progressive Education Translated out of Existence" as the target text. For the research itself, three questions have been formulated: Firstly, what is admissible in this 'translation system'? Secondly, why was the article 'translated' into Translation Studies? Thirdly, how could theoretical perspectives of Translation Studies enrich researchers' understanding of neighboring phenomena? ${ }^{1}$

At this stage, how the product is classified is not relevant for the theoretical framework

\footnotetext{
${ }^{1}$ Toury (1986) makes a distinction between "translating" and "translation": "translating is an overall inter- (or cross-) systemic type of information transmission." Accordingly, "texts, that are not regarded as translations according to the intrinsic norms of the target system may well include phenomena, or parts, which can be explicated as the output of translating procedures" (1120; original emphasis). The word translation and its collocations in single quotation marks refer to this potential throughout the paper unless otherwise stated.
} 
adopted here. Revised or translated, perspectives of the Translation Studies as an interdisciplinary field will be used for the research. It is believed that how the phenomenon has been classified may only have some bearing for evaluating research results.

\section{Theoretical Foundation}

A three-legged theoretical framework has been envisaged for the research. Since limits and explanatory force of intralingual translation will be explored, the first leg of the theoretical foundation is Roman Jakobson's ([1959] 2004) theoretical formulation. In "On Linguistic Aspects of Translation," he describes intralingual translation "or rewording" as "an interpretation of verbal signs by means of other signs of the same language" (114; original emphasis). Separate from interlingual and intersemiotic translation (114), rewording as a concept enables the investigation proposed here: the source and target texts are in the same linguistic but different disciplinary systems. However, it needs to be operationalized.

Accordingly, the second leg of the foundation is Gideon Toury's (2012) "notion of assumed translation" (26). The unit of analysis is not presented as a translation, but revision. For that reason, the analysis began with the assumption that it is a translation, albeit intralingual. Toury explains that he formulated assumed translation as a "working hypothesis" for two reasons. Firstly, it allows "a considerable expansion of the range of objects of study, in full agreement with those real-life situations we set out to account for." Secondly, it offers "functional operability even in cases where the basic principle might have seemed factually inapplicable" (26-8; original emphasis). If it were not for such an expansion and functional operability, revision would be discarded as non-translational annulling any need for further investigation. $^{2}$

The notion of assumed translation has three components: the source-text postulate, the transfer postulate and the relationship postulate (28). In Toury's words, "regarded as postulates, their existence is posited rather than factual, at least not of necessity. Therefore, rather than constituting answers, they are designed to give rise to questions, to be addressed by anyone wishing to study translation in context" (28; emphasis added). This logic guided

\footnotetext{
2 Berk Albachten (2019) in a later article finds Jakobson's concept limited to "linguistic equivalence alone" (chap. 10, under "Introduction"). In order to alleviate the linguistic "bias" in Jakobson's overall typology, Toury (1986) suggests taking into consideration "secondary modeling systems" (1113), i.e. "text-types, or textual traditions" (1116; original emphasis). The position adopted here is, hence, functional and, although closer to Berk Albachten $(2015,171)$, advocates further fruitful uses for the intralingual translation concept.
} 
the research from the beginning and since the natures of these postulates have already been confirmed, they will be presented as research results here. However, results do not have explanatory force by themselves. They are only meaningful if they form a pattern. Such a pattern has been sought after within a target-oriented framework. As a "teleological" activity (8), translating and its products have "position and functions" "in a prospective target culture" (18). Within that culture, "the form a translation would have (and hence the relationships that would tie it to its original), and the strategies resorted to during its production constitute an ordered set rather than a mere congeries of disconnected facts" and "reflect its [that culture's] own systemic constellation" (18; emphasis added). In this regard, with proper contextualization, "the point here is precisely to tackle questions such as why a text, or an activity, was (or was not) presented/regarded as translational" (28; emphasis added).

Within the target-oriented mindset, it is claimed that there is a specific target culture (subsystem or a sector within a system) in Alptekin's case which hosts her target text. And by asking right questions, investigating the postulates and collecting resulting data, it is believed that the researcher might show the pattern within that target culture, hence explain why this activity of revision was engaged in and not presented or regarded as translational.

In order to support that explanation, the third leg of the theoretical framework is formed with Gideon Toury (2002) again. In "Translation as a Means of Planning and the Planning of Translation: A Theoretical Framework and an Exemplary Case," as the title suggests, translation is taken "as much a means of effecting planning as it is a paradigmatic case thereof" (149; original emphasis). In this "socio-cultural" sense of planning as opposed to the "cognitive planning" in one's mind, translation is both "involved in the planning of other domains" and it is "amenable to planning in and for itself: from the very decision to translate and going all the way through to the establishment of individual linguistic replacements, whether they are taken from among the existing options of the target language or created anew" for "appropriate relationships" between replacing and replaced elements (149; emphasis added). Approached as planning, it is better explained why some choices have been adopted, because "PLANNING would consist in any act of (more or less deliberate) intervention in a current state of affairs within a social group, i.e., making decisions for others to follow, whether the impetus for intervening originates within the group itself or outside it" (151; original emphasis).

Within the theoretical framework outlined above, the relationship deemed appropriate 
transLogos 2018 Vol 1 Issue 1

Güneş, Alper Zafer, pp. 1-24

Translated in Translation Studies trans Logos

A Translation Studies Journal

(C) Diye Global Communications diye.com.tr|diye@diye.com.tr

between the target and source text and its results will also be evaluated. The textual analysis has been conducted at two levels, macro and micro. At both levels, text-type-specific features have been covered. With regard to the macro structure, the matrix, outline and introductory information of the texts have been included in the analysis. For the micro structure, aims, theoretical underpinnings, terminology, methodology, evaluation of results, discourse and voice of another actor ('translator'/reviser) have been discussed. ${ }^{3}$

\section{Macro Analysis}

The title of the target text is “John Dewey's 1924 Report on Turkish Education: Progressive Education Translated out of Existence.” It is written by Yasemin Alptekin (2015), Executive Director of American-Turkish Academy of Washington, and published in Tradition, Tension and Translation in Turkey, a book of Benjamins Translation Library. An epigraph is added: "How often misused words generate misleading thoughts" by Herbert Spencer from Principles of Ethics. In the abstract, the focus is on "the discrepancy between the English and Turkish versions of the term 'progressive education' as a philosophy of education, and the socio-political implications Dewey's report created in education then and at present in Turkey." Keywords of the article are "politics of translation, translated works on Turkish education, policies and leadership in Turkish education, progressive education, John Dewey" (181; emphasis added).

In the introduction of the editors, "the upheavals of the republican period and the clash between progressive and conservative forces and party politics" (emphasis added) are said to be "central to Yasemin Alptekin's illuminating article." Despite the fact that Dewey's report originally aimed at fostering "progressive education," readers are informed, “in its various translations into Turkish the emphasis on 'progressive' was ironically edited out and replaced by alternative phrasing or lexical terms (emphasis added)" (Tahir Gürçağlar, Paker, and Milton 2015a, 17).

The source text bears the title of "Can Progressive Education Be Translated into a Progressive Idea?: Dewey's Report on Turkish Education (1924).” The same author, Yasemin Alptekin (2006), was the Chair of Educational Sciences at Yeditepe University at the time. The article was published in an education journal, International Journal of Progressive

\footnotetext{
${ }^{3}$ For results of a similar analysis on a smaller scale see Güneş (2018).
} 
transLogos 2018 Vol 1 Issue 1

Güneş, Alper Zafer, pp. 1-24

Translated in Translation Studies trans Logos

A Translation Studies Journal

(C) Diye Global Communications diye.com.tr|diye@diye.com.tr

Education. The epigraph "How often misused words generate misleading thoughts" was transferred from the source text. In the abstract, it is stated that "the translated version [of Dewey's 1924 report] does not transform the idea of 'progressive education,' . . . instead [it has] remained to be a term that has been interpreted with different corresponding words in Turkish at different times." Transforming into an idea is present here as a different emphasis in line with the title. The source text is said to be concentrating on "the discrepancy between the English and Turkish versions of the term 'progressive' as a philosophy of education, and the implications Dewey's report created in teacher education along with non-progressive practices in the field of education in Turkey" (9; emphasis added).

By the source text's editor, the fact that "many Turkish officials, who held the top positions at the Ministry of Education after Ataturk's death in 1938, almost never seriously considered the recommendations in Dewey's report" is mentioned as different from the time of the article when "many Turkish educators and government officials start[ed] to consider implementing the principles of constructivist and progressive philosophy to Turkish education" (Eryaman 2006, 6).

"The upheavals of the republican period" and "the clash between progressive and conservative forces and party politics" statements, written to describe the focal points of the target text, reflect the "politics of translation" and "policies and leadership in Turkish education" keywords and the "socio-political" emphasis added to depict the implications of the translational actions performed for Dewey's report. These emphases in the target are not overtly expressed in the source. Instead, establishing progressive education as an idea, which was foreseen by Atatürk and only in the 2000s taken seriously again, strikes as a different emphasis surrounding the source text.

In terms of matrices of both texts, table 1 sheds light on the modification and distribution of textual material: 
Table 1 Matricial differences between the target and source texts

\begin{tabular}{|c|c|}
\hline Sou & \\
\hline $\begin{array}{l}\text { Subheadings - Number of Paragraphs - } \\
\text { Block Quotations } \\
\text { 1. Introduction }-2-1 \\
\text { 2. Method } 2-0 \\
\text { 3. Study } 3-0 \\
\text { 4. An Overview of Dewey's Work } \\
\text { Transtated into Turkish 1-0 } \\
\text { 5. Historical and Political Background to } \\
\text { Dewey's Visit }-6-1 \\
\text { 6. Dewey's Visit to Turkey }-9-2 \\
\text { 7. The Wording in the English Version of } \\
\text { the Report - } 4-1 \\
\text { 8. The Word "Progressive" in Dewey's } \\
\text { Other Translated Works } 3-0 \\
\text { 9. Past and Present Day Implications of } \\
\text { Dewey's Recommendations - } 3-1 \\
\text { 10. Conclusion - } 4-1\end{array}$ & $\begin{array}{l}\text { Subheadings - Number of Paragraphs - } \\
\text { Block Quotations } \\
\text { 1. Introduction }-7-2 \\
\checkmark \text { "Method" } \\
\checkmark \text { "Study" } \\
\checkmark \text { "An Overview of Dewey's Work } \\
\text { Translated into Turkish" } \\
\text { 2. The historical and political } \\
\text { background to Dewey's visit }-\mathbf{1 0}-1 \\
\checkmark \text { "An Overview of Dewey's Work } \\
\text { Translated into Turkish" } \\
\text { 3. Dewey' visit to Turkey - 8 - 3 } \\
\text { 4. The English wording of the report and } \\
\text { its Turkish correspondents - } 8-2 \\
\checkmark \text { "The Word 'Progressive' in } \\
\text { Dewey's Other Translated Works" } \\
\text { 5. Implications of the report in Turkish - } \\
\mathbf{9}-3 \\
\text { 6. Conclusion - 5 - 0 } \\
\text { 47 para., 11 block quotations } \\
\text { 34 Sources in References } \\
\text { 13 Footnotes }\end{array}$ \\
\hline
\end{tabular}

Every entry has been counted as a paragraph excepting block quotations. Although some subheadings seem to have been omitted in the target text, it is actually a re-organization. "Method" and "study" parts of the source text (ST) were incorporated into the "introduction" of the target text (TT). "An overview of Dewey's work translated into Turkish" in the ST was divided into the "introduction" and "the historical and political background to Dewey's visit" parts of the TT. "The word 'progressive' in Dewey's other translated works" was evaluated in "the English wording of the report and its Turkish correspondents" in the TT. In this regard, there are only two visible cases of increase in terms of the number of paragraphs. "The historical and political background to Dewey's visit" part has at least 3 more paragraphs and "implications of the report in Turkish" has 6 more paragraphs. Thus, it is plausible to claim that more contextual information has been added as evidenced by the increased number of paragraphs in background and implications sections. There is also an observable increase in the number of block quotations and works cited in the TT.

Since numbers of paragraphs and quotations have been counted with eye rather than an actual word counter, they might be misleading in terms of actual lengths of texts. For that 
transLogos 2018 Vol 1 Issue 1

Güneş, Alper Zafer, pp. 1-24

Translated in Translation Studies trans Dogos

A Translation Studies Journal

(C) Diye Global Communications diye.com.tr|diye@diye.com.tr

reason, both texts have been fed into Voyant Tools, a data visualization tool which allows to extract various data on texts. In order to have figures regarding the main body of articles, abstracts, key words, references, title and page number headers were removed, but footnotes were kept in each text file. Table 2 confirms an increase in the target document length.

Table 2 Voyant Tools results

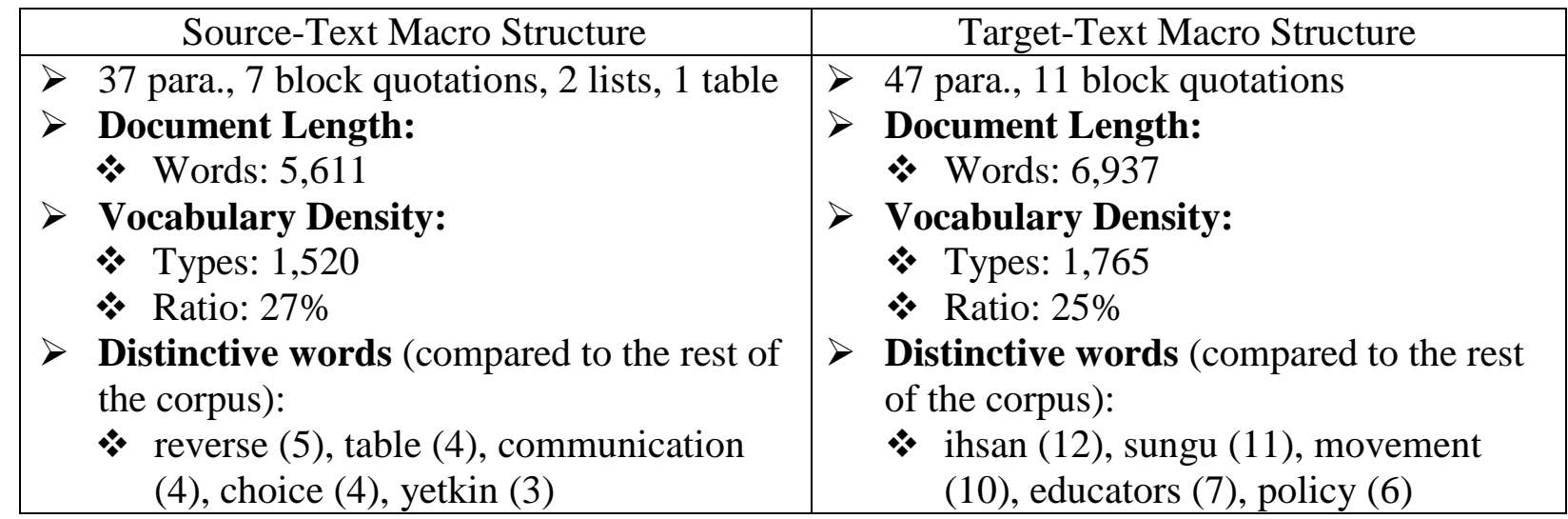

The term 'type' refers to the number of distinct words in the texts, and 'words' refer to 'tokens,' which are the total number of words in each text file. The TT has around 250 more distinct words and is longer by around 1,300 words. Due to its length, the linguistic richness of the TT, acquired by the ratio of types to tokens, is slightly less than the ST's. In terms of distinctive words each text harbors, there is a shift from 'communication' to 'movement' and 'policy.' Interestingly, 'educator' as an agent noun was not used in the ST despite the fact that the source is in the field of education. Also, the name 'İhsan Sungu' appears in the TT. These groups of data are significant in the sense that they piece together little by little what is specific about the target text, what changed during the transfer into Translation Studies and ultimately what is acceptable therein in line with the research questions.

The last group of macro structural data concerns the number of works cited and footnotes given in table 3 below. 
Table 3 Number of works cited and footnotes

\begin{tabular}{|c|c|}
\hline Source-Text Macro Structure & Target-Text Macro Structure \\
\hline $\begin{array}{l}25 \text { Sources in References } \\
4 \text { sources not cited in text } \\
5 \text { sources cited in text but missed in } \\
\text { references }\end{array}$ & $\begin{array}{l}\text { 34 Sources in References } \\
\quad 8 \text { omitted (4 not-cited-in-text sources) } \\
\text { - } 17 \text { added } \\
\text { - } 4 \text { cited-but-missed-in-references } \\
\text { - } 2 \text { neurces } \\
\text { - } 1 \text { Ottoman source }\end{array}$ \\
\hline $\begin{array}{l}11 \text { footnotes } \\
2 \text { modified in TT } \\
5 \text { omitted in TT } \\
* \text { others incorporated into TT }\end{array}$ & $\begin{array}{l}\quad 13 \text { footnotes } \\
\quad 7 \text { new sources introduced in } 5 \\
\text { footnotes }\end{array}$ \\
\hline
\end{tabular}

13 new works cited in the TT suggest an enlargement of the research, and interestingly 7 of them were cited in footnotes separate from the main body of argument. ${ }^{4}$ Omitted footnotes from the ST will also be elaborated in the micro analysis.

\section{Micro Analysis}

For this part of the analysis, features relevant to a scientific paper have been located and analyzed in isolation with the aim of establishing a systemic pattern for the TT. In the micro analysis, aims, theoretical underpinnings, terminology, methodology, evaluation of results, discourse and voice of another actor ('translator'/reviser) have been discussed. The results will be presented in tables comparatively, where possible, to facilitate following arguments.

\subsection{Aim}

The aim had been kept invariant during the 'translation process' into the Translation Studies (TS). Only the translational nature of the report was emphasized differently in the TT as shown in table 4 .

\footnotetext{
${ }^{4}$ Counting works cited was not straightforward and followed a certain logic. In Alptekin (2006), different editions of Günyol's Freedom and Culture translation are mentioned in the text and the 1987 translation is used for analysis (12, 17). In its References, only the English title is listed (20). In Alptekin (2015), two different editions are listed and the English title is changed with the French translation (197). Considered more crucial, only the 1987 edition was counted as "missed in references" for Alptekin (2006), for instance.
} 
Table 4 Aims of both texts

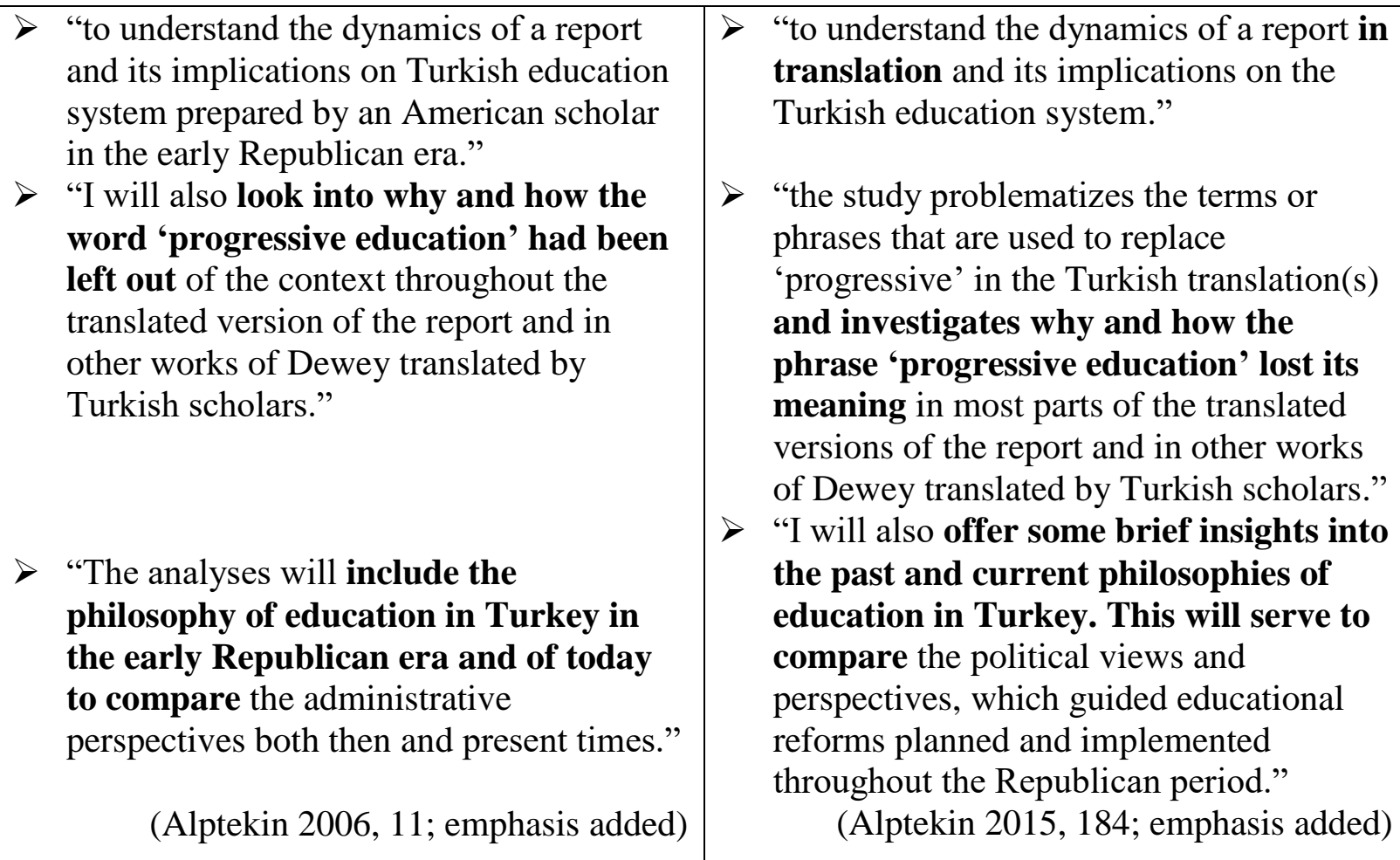

\subsection{Theoretical Underpinning}

Some shifts have been observed as for the theoretical underpinnings of both texts as highlighted in table 5. Referring to the same source, some points were omitted, added or changed from a linguistic understanding to a contemporary TS perspective. These alterations manifest themselves as an emphasis on "cultural" in addition to linguistic differences, omission of translation as a possible "impediment" in communication, omission of dated dichotomy between word-for-word and sense-for-sense translation strategies for a "contextually sensitive" translation, or a shift from "historical conjunction" to a "historically different context" in line with other decisions.

Table 5 Theoretical underpinnings of both texts

Study: "Cross-cultural exchange of ideas does not always translate into the best corresponding meaning of words and terms in the target language due to the syntactic and lexicological differences between the target language and the source language. Therefore, more often than we realize, the message
The English wording of the report and its Turkish correspondents: "Cross-cultural exchanges of ideas do not always translate into the best corresponding meaning of words and terms in the target language due to the syntactic, lexicological and cultural differences between target and source 
received may not be decoded with the same emphasis and intention of the word used in the encoded language. Translation creates interlingual impediments in the transformation of ideas from one language to another." (Alptekin 2006, 11; emphasis added)

Study: "Following a similar line of thinking with Malmkjaer, it is appropriate to say that the word 'progressive' in the report was not translated as word-for-word translation for accuracy, but rather, sense-for-sense translation for creativity in both versions of Turkish translation." (Alptekin 2006, 11; emphasis added)

Dewey's Visit to Turkey: "Again, it is obvious that what Dewey was trying to achieve at the American elementary school within his progressive school project in Chicago was in an historical conjunction with what needed to be done in Turkey for Turkish education." (Alptekin 2006, 14; emphasis added)

In the same manner with the theoretical considerations, terminology also changes in the 'translation process' into the TS: "reverse translation" (15) and "re-writing" (17) in Alptekin (2006) changes to "back translation" (191) and "re-wording" (182), respectively, in Alptekin (2015); "verbatim transliteration" (182) appears in the latter in accordance with methodological differences elaborated below; "agents of social change" (196) and "assimilating" (196) were also added to the latter as per theoretical concerns.

\subsection{Methodology}

With regard to the methodology, major additions in the 'translation process' were the introduction of an Ottoman translation and its translator as İhsan Sungu. In both texts of Alptekin $(2006,15 ; 2015,182)$, two reports written by Dewey are mentioned. In the ST, two conflicting views regarding their publication are mentioned. According to a source, "the reports have been printed four times since they were first issued, two of them by the journal of Ministry of Education in 1925 and 1928"; however, according to another source, "the same 
transLogos 2018 Vol 1 Issue 1

Güneş, Alper Zafer, pp. 1-24

Translated in Translation Studies trans Dogos

A Translation Studies Journal

(C) Diye Global Communications diye.com.tr|diye@diye.com.tr

reports are said to be published jointly by the Ministry of Education in 1939 for the first time" and the translator is unknown $(2006,10)$. The first source is not followed and the 1939 is taken as the first "translation of the Report" published "fifteen years after its preparation" (2006, 17). The 1939 Turkish version of the report gets destroyed in a 1946 fire and reprinted in $1952(2006,14 ; 2015,189)$. The 1987 version is said to be "not a re-translation of the original text but a re-write of the earlier translation in modern Turkish" following an interview with its translator Vedat Günyol $(2006,17)$. Lastly, the English version of Dewey is claimed to have been lost until 1960 and first published in full in 1983 (2006, 14; 2015, 189).

In the TT, Alptekin (2015), as different from the ST, the first source stated above seems to have been followed and an Ottoman translation of the report from 1925 was located "in two parts in the first two issues" of the Journal of the Ministry of Education (182). On the copies found at the National Library in Ankara, "the stamp reads 'İhsan Sungu Kitaplığı' ['from the library of İhsan Sungu'] in Latin script (original brackets)" and although he was not named as the translator on any of the reports' Turkish versions, he is claimed to be the translator of the 1925 version, because "there are several other articles of Dewey that were translated and signed by "İhsan"” (186). All details regarding this potential translator are introduced in footnotes 5,6 and $8(183,184,186)$. After establishing a prior translation in Ottoman script, the 1939 version is accordingly dubbed as "a verbatim transliteration of the 1925 translation into the Latin script" and gets "reprinted in 1952"; the 1987 version is stated to be a "re-wording in modern Turkish" (182; emphasis added).

Understandably for an article in the field of education, the fact that originals were absent until 1960 is not problematized. If they had not been located in the archives, retranslation from the same STs was already not a possibility, which means any Turkish translations could only have been intralingual or indirect from an intermediary text. Furthermore, a 1939 translation/transliteration is claimed to have been reprinted in 1952 . However, the same 1939 version was destroyed in a 1946 fire. This confusion is also found in the references of both texts. The ST lists "1954 [sic]" for "Türkiye Maarifi Hakkında Rapor," which is Dewey's "Report on Turkish Education" (Alptekin 2006, 20) and the TT lists "1939" as the date of the same text with a slight change in the title "Türk Maarifi Hakkında Rapor" (Alptekin 2015, 197). The TT adds the 1925 Ottoman source in the references with the same title as the 1939 entry. Both articles do not specifically refer to Dewey's English reports in their references, but state in the texts that they are located in the "Volume 15 of The Middle 
transLogos 2018 Vol 1 Issue 1

Güneş, Alper Zafer, pp. 1-24

Translated in Translation Studies trans Logos

A Translation Studies Journal

(C) Diye Global Communications diye.com.tr|diye@diye.com.tr

Works, 1899-1924" (Alptekin 2006, 14; 2015, 190). Interestingly, the questions of which source texts were used for the translational practices analyzed and how they affected the resulting target texts have not been answered in both articles. Source text is a relevant issue, because omissions or replacements of the term 'progressive' in these translations, which is the focal point of the articles, might be accidental due to source texts as possible variables in decision-making.

In light of all the data combined from both articles, there is the 1925 Ottoman translation, the 1952 Latinized version and the 1987 reworded version, which are available for analysis. Unless found in some archives before 1960, chronologically the English originals, published in 1983, could only be available to Vedat Günyol and Günyol, in the interview of May 30, 2004 with Alptekin (2006), states "he hardly used the original version in English as the source, rather he re-wrote the original translation in modern Turkish as he also referred to a text of the report in French" (17). This leaves us with the 1925 interlingual and potential 1952 and 1987 intralingual translations unless new data are provided.

Alptekin (2006) mentions the visit to Günyol to ask "why he translated 'progressive' in seven different ways" and "the day," is said to have been, "documented with photos and with two other colleagues" (17). The interview is mentioned in two footnotes, the 4th and 10th $(11,17)$. In Alptekin (2015), references to the interview are merged and modified in footnote 3 (182-183). Günyol's comments have been omitted and the following details added after some background information on him:

In his translation there is no reference as to whether it was from a French version or the English source text. However Günyol is known to have been a translator of French and not of English. The French of Freedom and Culture, which may well have served as the source for Günyol, appeared in 1955 as Liberte et Culture, translated by Pierre Messiaen." (Alptekin 2015, 182-3; emphasis added)

Despite being published in the field of education, the ST can be said to be following a more rigorous methodology, in this regard, also by including contexts and specifying which segments belong to which texts. Since Alptekin (2006) takes the 1939 version as the first translation, she only compares the 1939 (or alleged 1952 reprint) and 1987 translations with the original report (11) in terms of their "wording" for "progressive" (15). The results are presented in a table with "reverse" translations by the author (15). Original contexts are added as a separate list (16). "Discrepancies" between the source and translations are pointed out 
(17) and how "progressive" has been and should be translated are exemplified via other Dewey works (17-18).

In Alptekin (2015), the 1925 Ottoman translation has been added to the research but the comparison is conducted via its 1939 (or 1952) verbatim transliteration. Although the researcher informs "the first 1925 translation (in Arabic script) [is compared] both with the 1939 (and 1952) transliterations and the 1987 reworded version" (184), the presentation of results suggests that the 1925 and the 1939 (1952) texts are taken to be the same, because which segments belong to which texts are not specified in the textual comparison. This issue becomes critical in the case of a discrepancy concerning the same segment in two articles: as translations of "industrial progress," "sanatçı terakkiye" in the 1939 (1952) version and "sanatçı ilerleme" in the 1987 version are listed by Alptekin (2006) with a back translation of “artistic progress" (15). In Alptekin (2015), that translation becomes "san'atçe terakki" (190) with no further references to a specific text. Moreover, only one paragraph from the original, its translation and back translation within context were offered by the scholar for the Translation Studies article (191). Similarly, "the 1987 re-worded modern Turkish version," informs Alptekin, "further omits the term" (191) and only back translations for words replacing the word progressive are listed. As in the ST, the TT also cites some other translated works of Dewey to see how they translated progressive education (192). Table 6 illustrates how the ST followed a more meticulous methodology despite its educational background:

Table 6 Presentation of textual comparisons

\begin{tabular}{|c|c|c|c|c|}
\hline "English" & $\begin{array}{l}\text { "1939 ('52) } \\
\text { Translation" }\end{array}$ & $\begin{array}{l}\text { "1987 } \\
\text { Translation" }\end{array}$ & $\begin{array}{l}\text { "Reverse } \\
\text { Translation (of } \\
\text { '87 version)" }\end{array}$ & \multirow{3}{*}{$\begin{array}{r}\text { (Alptekin } 2006 \\
15 ; \text { original } \\
\text { emphasis) }\end{array}$} \\
\hline $\begin{array}{l}\text { "progressive } \\
\text { development" }\end{array}$ & $\begin{array}{l}\text { "mütekamil } \\
\text { inkişaf" }\end{array}$ & $\begin{array}{l}\text { "yetişkin } \\
\text { gelişme" }\end{array}$ & $\begin{array}{l}\text { "mature } \\
\text { development" }\end{array}$ & \\
\hline $\begin{array}{l}\text { "industrial } \\
\text { progress" }\end{array}$ & $\begin{array}{l}\text { "sanatçı } \\
\text { terakkiye" }\end{array}$ & $\begin{array}{l}\text { "sanatçı } \\
\text { ilerleme" }\end{array}$ & $\begin{array}{l}\text { "artistic } \\
\text { progress" }\end{array}$ & \\
\hline \multicolumn{4}{|c|}{$\begin{array}{l}\text { "Let us consider the combinations where 'progressive' was used in the } \\
\text { English reports (with the Turkish in parenthesis): ... 'progressive } \\
\text { development' [mütekamil inkişaf], 'industrial progress' [san'atçe terakki] } \\
\text {..." }\end{array}$} & \\
\hline \multicolumn{4}{|c|}{$\begin{array}{l}\text { "the inherent meaning of 'progressive' is lost in all seven attempts [in the } \\
1987 \text { re-worded version], changing from 'developed' to 'advanced' to } \\
\text { 'mature' to 'improved' to 'experienced' and finally to 'perfect."' }\end{array}$} & $\begin{array}{r}\text { (Alptekin 2015, } \\
\text { 190-191; original } \\
\text { brackets) }\end{array}$ \\
\hline
\end{tabular}




\subsection{Evaluation of Results}

Following the new theoretical directions, the results are evaluated under a different light in the TT. In Alptekin (2006), müterakki is stated as the "best choice" for "progressive" (17), but in Alptekin (2015) the emphasis is placed on terakki as the closest word to "progress" (190) for a "contextually sensitive" (192) evaluation (see table 7).

Table 7 Connotations of terakki in 1925

"Although there is not a major discrepancy among the meanings of those three words (i.e., müterakki, mütekamil, terakki) the word müterakki is the best choice for the purpose signified by the word 'progressive."” (Alptekin 2006, 17)

"Although there is no major discrepancy
between the meanings of these three words
(i.e., [müterakki]: that which progresses;
[mütekamil]: mature; [terakki]: progress), the
word terakki is closer to the word 'progress."'
(Alptekin 2015, 190; original brackets)
"The terms 'müterakki' and 'terakkiperver,'
both meaning 'progressive' in the Turkish
discourse of the period, did not agree with
the socio-political connotations and climate
of the times. We should keep in mind that the
Progressive Republican Party was founded in
September 1924 and closed down in June
1925, that Dewey completed his visit and left
Turkey in September 1924, and that the
translation of Dewey's reports was published
in 1925." (Alptekin 2015, 195; emphasis
added)

Alptekin (2006) believes "the absence of an accurate translation for 'progressive education' in Dewey's reports on Turkish education was inadvertent"; because "educational jargon ... was not clear enough even in the United States at the time" (19). This evaluation in table 8 is parallel to Günyol's comments regarding his various translations for the word 'progressive'. He had stated that "he hardly used the original version in English as the source, rather he re-wrote the original translation in modern Turkish as he also referred to a text of the report in French" (17; emphasis added). In Alptekin (2015), it is claimed that "İhsan Sungu and Vedat Günyol, saw themselves as agents of social change and the field of education as a platform for creating the kind of social change they conceptualized" (196). However, the fact that İhsan Sungu could not be confirmed as the actual translator of the 1925 Ottoman translation might have been factored in that evaluation. 
Table 8 Agents of social change

\begin{tabular}{|c|c|}
\hline $\begin{array}{l}\text { "the absence of an accurate translation for } \\
\text { 'progressive education' in Dewey's reports } \\
\text { on Turkish education was inadvertent since } \\
\text { the word 'progressive' was not perceived as a } \\
\text { rubric for a school of thought. It may be } \\
\text { totally due to lack of understanding by the } \\
\text { translator what was meant by 'progressive } \\
\text { education' as an educational jargon since it } \\
\text { was not clear enough even in the United } \\
\text { States at the time" (Alptekin 2006, 19; } \\
\text { emphasis added) }\end{array}$ & $\begin{array}{l}\text { "this [Dewey's] concept was suppressed, } \\
\text { neutralized, and even 'depoliticized.' } \\
\text { However, since the translators of Dewey's } \\
\text { reports, İhsan Sungu and Vedat Günyol, saw } \\
\text { themselves as agents of social change and } \\
\text { the field of education as a platform for } \\
\text { creating the kind of social change they } \\
\text { conceptualized, in their positions as official } \\
\text { government translators and bureaucrats, i.e. } \\
\text { the elite, they took the liberty of } \\
\text { 'assimilating' the original idea to match } \\
\text { what they considered the 'needs of } \\
\text { society."' (Alptekin 2015, 196; emphasis } \\
\text { added) }\end{array}$ \\
\hline
\end{tabular}

The evaluations of the articles not only reflect their theoretical differences but also the significations of their titles. The communicative aspect of translation appears once again in the ST evaluations: Translation alone may not be enough to communicate a new idea, which requires involvement of all groups (Alptekin 2006, 18-19). In the TT, what is evident is the deliberate erasure of the concept of "progressive education" in translations. These different emphases are read in the titles as well (see table 9).

Table 9 Communication vs. agency

\begin{tabular}{|c|c|}
\hline $\begin{array}{l}\text { Source Title: "Can Progressive Education } \\
\text { Be Translated into a Progressive Idea?: } \\
\text { Dewey's Report on Turkish Education } \\
\text { (1924)" (emphasis added) }\end{array}$ & $\begin{array}{l}\text { Target Title: "John Dewey's } 1924 \text { Report on } \\
\text { Turkish Education: Progressive Education } \\
\text { Translated out of Existence" (emphasis } \\
\text { added) }\end{array}$ \\
\hline $\begin{array}{l}\text { "In a cross-cultural exchange of ideas, the } \\
\text { activity of translation, once left alone, may } \\
\text { not be the best tool to achieve } \\
\text { communication of a totally new idea or } \\
\text { perspective." (Alptekin } 2006,19 \text {; emphasis } \\
\text { added) }\end{array}$ & \multirow{2}{*}{$\begin{array}{l}\text { "the translations articulate a reform in } \\
\text { education as a top-down practice that is } \\
\text { regulated and regimented by the government } \\
\text { with a vague idea of 'progressive education,' } \\
\text { that is, one emptied of the component of } \\
\text { individual freedom and other democratic } \\
\text { practices as a major education movement." } \\
\text { (Alptekin } 2015,195 \text {; emphasis added) }\end{array}$} \\
\hline $\begin{array}{l}\text { "A systemic change requires the } \\
\text { communication, participation, cooperation, } \\
\text { and dedication of all parties involved [rather } \\
\text { than a top-down imposition]." (Alptekin } \\
\text { 2006, 18-9) }\end{array}$ & \\
\hline
\end{tabular}

At this stage, it is possible to say that there is a clear change of focus from 'communicative' function of translation to the 'agency' thereof. Combined with the macro 
analysis, this result gains more accuracy: the keyword 'communication' was absent in the TT and therein appeared 'movement,' 'policy' and 'educators.' On theoretical levels, the 'sociopolitical' context was highlighted, 'culture' was included and the translation phenomenon was situated in a 'historically different context' from the original. As we shall see now, this context was also constructed differently as hinted in the introduction of the TT editors: "the upheavals of the republican period and the clash between progressive and conservative forces and party politics" (Tahir Gürçağlar, Paker, and Milton 2015a, 17; emphasis added).

\subsection{Political Discourse}

In the discourse of the ST, there is a favorable atmosphere for Dewey's reports in the receiving culture during Atatürk's time. This is reflected in its editor's words quoted above (Eryaman 2006, 6), in Dewey's comments and in similarities between Atatürk and Dewey's ideas (Alptekin 2006, 12-13). The discourse is revised for the TT and the Terakkiperver Cumhuriyet Firkasl (Progressive Republican Party) is foregrounded underlining its negative connotations at odds with development. The ST touches upon terakkiperver and the political party only in passing as quoted in table 10 .

Table 10 Progressive opposition party

'In a 'reverse translation,' Lord Kinross uses the word 'progressive' for an opposition party founded in March 1924. The original name of the political party in Turkish is Terakkiperver, which means 'those who like progress' or 'progressive.'” (Alptekin 2006, 17; emphasis added)
"The irony also lies in the name of the party: the founders were neither progressive nor republican since they found the reforms to be too rapid and sided with those who were rebelling against the secular state.... The party left the political scene, also leaving behind the word 'progressive' [terakkiperver] (original brackets), associated with a futile practice loaded with negative connotations." (Alptekin 2015, 187-8; emphasis added)

In such a target-text context, the emphases were also rearranged. The following quotation from Dewey's (1924) "Secularizing a Theocracy" is found in both articles (Alptekin 2006, 12; 2015, 187), but the italicized line depicting a favorable context was further omitted in the TT.

In the United States and in western Europe the abolition of the Caliphate, the closing of the mosque schools and the assumption of the revenues of the pious Moslem 
foundations aroused misgivings as well as amazement. Was not the new republic going too fast? . . . (original ellipsis points) Upon the ground, in Constantinople, perhaps the most surprising thing is the total absence of all such misgivings and queries. The move appears a simple, natural, inevitable thing. It presents itself as an integral and necessary step in the process of forming a national state after the western model. To question it . . . (quoted in Alptekin 2006, 12; emphasis added)

Finally, after being quoted in the ST as "the right man, at the right place to give advice” from Wolf-Gazo’s (1996) “John Dewey in Turkey: An Educational Mission” (quoted in Alptekin 2006, 14), Dewey sees his "faith in democracy and freedom" not in agreement with "the geo-political and socio-political circumstances of contemporary Turkish society" in the TT (Alptekin 2015, 192).

It is as if there are two voices in the TT which are not always in agreement. Having the ST at hand, it is possible to discern voices of the author and another actor ('translator'/reviser) in the TT through discourse analysis. The voice of another actor may also be associated with the introduction of new sources in footnotes rather than intervening in the voice of the author further ( 7 new sources were added in 5 footnotes). However, that disagreement or intervention appears to have created some discrepancies not only between the target and source texts but within the target text itself.

\subsection{Discrepancies}

Firstly, the similarity between Atatürk and Dewey's ideas is actually mentioned in both texts: "Dewey met with Mustafa Kemal Atatürk. . . . Atatürk's and Dewey's ideas about [on] development and progress were similar" (Alptekin 2006, 13; 2015, 188). Contrary to that similarity, in the TT alone, it is also asserted, "the discourse [on progressive education] is more of a reflection of the statist and centralist behavior inherent in the Turkish reforms of the early Republican period which persists to this day" (Alptekin 2015, 195).

As a second point, the author does not agree with a Dr. Fay Kirby who stated that each foreign scholar including Dewey "saw Turkey as an extension of his own country" and for that reason it would not be possible for them to help in a realistic manner (Alptekin 2006, 14; 2015, 192). Alptekin (2015) specifically reiterates her position writing "I do not agree with Kirby on the issue as I believe Dewey was much more interested in where Turkish people were headed for with the Republican government-introduced reforms than from where they had come" (192). However, one of the conclusions of the TT contradicts this position: 
At this point, one might ask the question as to which was more unrealistic or naive here. Dewey's attempt to transmit a philosophical idea created in his own culture and social context into a foreign one, and expect it to be accepted there as it was, or his translators' attempt to render a philosophically foreign idea into their own culture, assimilating it into an already prescribed social context to create a common ground between the foreign idea and the "national needs."' (Alptekin 2015, 196; emphasis added)

In Alptekin's shift from the "historical conjunction" (2006, 14) to "historically different context" $(2015,196)$ between Chicago and Turkey, her discourse in the 'translated' version changes as well.

\section{Research Results}

With regard to the first research question - What is admissible in this 'translation system'? - it is now plausible to conclude that there is a divergence between the data and the theoretical framework. Since Vedat Günyol does not consult the English source but rewrites the existing translation in modern Turkish, Alptekin (2006) deduces that his choices were unintentional. As the same data are also valid for Alptekin (2015), it is not feasible to talk about an active agency of Günyol and there is only a probability that İhsan Sungu is the translator of the 1925 version.

Additionally, target and source text variables were not problematized enough. The Ottoman text was acquired from the National library archives for Alptekin (2015). However, relationships between segments were not connected to specific target texts as illustrated in the case of san'atçe terakki. Since its spelling and possibly meaning is conceived differently in Alptekin (2006) due to the Ottoman language factor, the target text issue becomes a critical methodological variable. Various facts, such as the burning of the 1939 version, nonexistence of Dewey's originals until at least 1960 and their being published in 1983, make the 1925 version an interlingual and 1952/1987 versions possible intralingual translations. Thus, the source text issue also needs to be included as a variable for translational decisions. All in all, lack of some research protocols went unnoticed in the 'translation process' into the Translation Studies.

The answer to the second question - Why was the article 'translated' into Translation Studies? - is found in the preface of Tradition, Tension and Translation in Turkey. The aim of the volume was stated to “situate Turkey's important translation landscape and legacy on the 
world's translation studies map." For that aim, "contributions from a number of established and emerging scholars representing diverse facets of translation research on Turkey" were included in the volume so that it would be "the most comprehensive one ever concerning translation in Turkey" and would "serve as a point of reference for international and Turkish readers alike" (Tahir Gürçağlar, Paker, and Milton 2015b, vii-viii). However, there are also less-represented areas which need more research: "The part it [translation] played in the transmission and dissemination of political and philosophical thought and education, for instance, have yet to be thoroughly analyzed in the context of interdisciplinary research" (Tahir Gürçağlar, Paker, and Milton 2015a, 1).

In this regard, remembering Toury's (2002) article formulating translating as a means of planning and an exemplary case of planning, the decision to 'translate' Alptekin's article is only logical for the volume's aims. Toury reminds, "cultures resort to translating as one possible way of filling in gaps in them - on a variety of levels" (2002, 153; original emphasis). Items to be used for the filling-in could be "textual entities" or "hitherto non-existing models" "in more complex cases" (153-4; original emphasis). On that account, Alptekin's research area and 'translation' of her article aimed to function as a model for future studies by filling in a perceived gap in translation research.

The third question - How could theoretical perspectives of Translation Studies enrich researchers' understanding of neighboring phenomena? - is also the justification of conducting this research within the TS. As early as 1985, Theo Hermans writes, "from the point of view of target literature, all translation implies a degree of manipulation of the source text for a certain purpose" (11). The label revised may disguise its translational nature and a whole set of political and cultural relations behind it, and a TS approach is equipped with revealing such manipulations. The word manipulation may seem like a strong word for the transfer of theoretical models and scientific studies, but it is not an unaddressed issue in the TS.

Şebnem Susam-Sarajeva (2002), in “A 'Multicultural' and 'International' Translation Studies?", "questions certain import/export relations between the center and periphery of translation studies" (193). Susam-Sarajeva conveys that the center produces "the models and tools" "by using central data" and in its claim for "universality and all-inclusiveness," "peripheral systems" are needed "to increase the variety of material available for scrutiny" (193-4). Within this system, "if any contribution is expected from them [new generation of 
researchers from the periphery], it can only follow the wholesale internalization of central translation theories as the only conceivable and legitimate provider of models in contemporary translation studies" (196; original emphasis). Susam-Sarajeva dubs that condition as "standard 'initiation and socialization process into an academic community" and informs that it is a "widespread pattern" and not specific to the TS (197). "What matters at this point is no longer the intrinsic quality-relevancy, efficiency or usefulness - of the models, tools or theories exported by the centre, but rather the authority and power which accompany this process" (198; emphasis added).

The result of these relations is "the widespread and mostly voluntary effort to mime the dominant powers, to mould the indigenous discourses on the model of imported knowledge" (198). As further consequences, "researchers are 'educated away' from their own culture and society" (199) and periphery researchers literally "translate their material mostly from their own culture of origin - into the dominant paradigms and discourses of contemporary translation studies" (200; emphasis added). Besides, since they "cannot afford to leave certain historical, literary, social or political information implicit . . ., research on peripheral systems is often full of background information" (200; emphasis added) like the contextual additions revealed in macro analysis in this research. Susam-Sarajeva suggests focusing on home "languages and cultures in terms of translation theory" to see what has been or being carried out therein in place of providing data for the center (204; original emphasis).

Not surprisingly, this final call is in line with the comments of Senem Öner (2016) in her review for Tradition, Tension and Translation in Turkey. Reminding Ayşe Banu Karadağ's (2008) findings regarding “the absence of the term/concept 'civilization' as an explanatory tool in the historical/theoretical research on the relationship between translation and Turkish modernization", Öner quotes Karadağ's emphasis on Itamar Even-Zohar's cultural approach as a possible reason. She proposes, this "absence" "attests to another tension in the Turkish context caused by 'translated' theories of translation" (384; emphasis added).

In conclusion, in line with the hypothesis that revision can be analyzed as a translational activity with the tools of Translation Studies as an interdiscipline ${ }^{5}$, it was

\footnotetext{
${ }^{5}$ Esra Birkan Baydan (2018) leads a thought-provoking discussion on interdisciplinarity in Translation Studies rereading Holmes' (1972) “The Name and Nature of Translation Studies" from a contemporary viewpoint (81). Concurring with her suggestion (98), this study hopes to induce similar self-reflexivity in other disciplines as an
} 
transLogos 2018 Vol 1 Issue 1

Güneş, Alper Zafer, pp. 1-24

Translated in Translation Studies
transLogos

A Translation Studies Journal

(C) Diye Global Communications diye.com.tr|diye@diye.com.tr

proposed that the manipulative nature of translating is also inherent in the case of scientific writings and observable in the application of theories. After validating research proposals, it is reasonable to suggest now, in order to minimize the pitfalls of manipulations or at least acknowledge them, there is a need for reading theoretical frameworks afresh with an emphasis on local dynamics and a strong scientific reasoning. 
transLogos 2018 Vol 1 Issue 1

Güneş, Alper Zafer, pp. 1-24

Translated in Translation Studies trans Logos

A Translation Studies Journal

(C) Diye Global Communications diye.com.tr|diye@diye.com.tr

\section{References}

Alptekin, Yasemin. 2006. "Can Progressive Education Be Translated into a Progressive Idea?: Dewey's Report on Turkish Education (1924)." International Journal of Progressive Education 2 (1): 9-21.

. 2015. “John Dewey's 1924 Report on Turkish Education: Progressive Education Translated out of Existence.” In Tahir Gürçağlar, Paker, and Milton 2015, 181-198.

Berk Albachten, Özlem. 2015. "The Turkish Language Reform and Intralingual Translation.” In Tahir Gürçağlar, Paker, and Milton 2015, 165-180.

. 2019. "Challenging the Boundaries of Translation and Filling the Gaps in Translation

History: Two Cases of Intralingual Translation from the 19th-century Ottoman Literary Scene." Chap. 10 in Moving Boundaries in Translation Studies, edited by Helle V. Dam, Matilde Nisbeth Brøgger, Karen Korning Zethsen. London: Routledge. Google Book.

Birkan Baydan, Esra. 2018. "Disiplinlerarasılıktan Ne Anlamalıyı?" [Interdisciplinarity in Translation Studies]. In Çeviribilimde Güncel Tartışmalardan Kavramsal Sorgulamalara [From recent discussions to conceptual reflections in Translation Studies], edited by Seda Taş, 81-100. Istanbul: Hiperyayın.

Eryaman, Mustafa Yunus. 2006. "Editorial Statement." In International Journal of Progressive Education 2 (1): 6-8.

Güneş, Alper Zafer. 2018. “A Translation System within Translation Studies.” Paper presented at the Enriching Translation Studies through Rereadings Symposium, Istanbul, March 28.

Hermans, Theo. 1985. "Introduction: Translation Studies and a New Paradigm." In The Manipulation of Literature: Studies in Literary Translation, edited by Theo Hermans, 7-15. London: Croom Helm.

Jakobson, Roman. (1959) 2004. "On Linguistic Aspects of Translation.” In The Translation Studies Reader, edited by Lawrence Venuti, 113-118. London: Routledge.

Karadağ, Ayşe Banu. 2008. Çevirinin Tanıklı̆̆ında 'Medeniyet'in Dönüşümü. [Transformation of 'civilization' in the witness of translation]. Istanbul: Diye.

Öner, Senem. 2016. Review of Tradition, Tension and Translation in Turkey, edited by Şehnaz Tahir Gürçağlar, Saliha Paker and John Milton. The Translator 22 (3): 382-386. doi:10.1080/13556509.2016.1183181.

Susam-Sarajeva, Șebnem. 2002. "A 'Multicultural' and 'International' Translation Studies?" In Crosscultural Transgressions: Research Models in Translation Studies II, edited by Theo Hermans, 193-207. Manchester: St. Jerome. 
transLogos 2018 Vol 1 Issue 1

Güneş, Alper Zafer, pp. 1-24

Translated in Translation Studies trans Dogos

A Translation Studies Journal

(C) Diye Global Communications diye.com.tr|diye@diye.com.tr

Tahir Gürçağlar, Şehnaz, Sahila Paker and John Milton. 2015a. "Introduction." In Tahir Gürçağlar, Paker, and Milton 2015, 1-24. Amsterdam: John Benjamins.

2015b. "Preface." In Tahir Gürçağlar, Paker, and Milton 2015, vii-ix. Amsterdam: John Benjamins.

—, eds. 2015c. Tradition, Tension and Translation in Turkey. Amsterdam: John Benjamins.

Toury, Gideon. 1986. "Translation: A Cultural-Semiotic Perspective." In Encyclopedic Dictionary of Semiotics, edited by Thomas A. Sebeok, 1111-1124. Berlin: Mouton de Gruyter.

2002. "Translation as a Means of Planning and the Planning of Translation: A Theoretical Framework and an Exemplary Case." In Translations: (Re)shaping of Literature and Culture, edited by Saliha Paker, 166-174. Istanbul: Boğaziçi University Press.

2012. Descriptive Translation Studies and Beyond. Rev. ed. Amsterdam: John Benjamins. 